\title{
INTRODUCTION TO PLASMA THEORY
}

\section{Dwight R. Nicholson, University of lowa}

Clearly written, this text gives students a complete introduction to all important topics in plasma theory. And none of the mathematical steps are skipped in the derivations. Easyto-follow introductions are given to such modern topics as solitons, parametric instabilities, and weak turbulence theory. Each chapter ends with a set of well-chosen problems which apply the theory to practical examples and short exercises which assist in

To be considered for complimentary copies, write to Clayton Gordon, Dept. 3-8590. Please include course name, enrollment, and title of present text. the learning process. 144 illustrations are included to clarify the mathematical development and a table of important practical formulas can be found inside the front cover of the book.

Suitable for both a one year graduate course or a one semester senior level undergraduate course. approx. 448 pp. (0 471-09045-X)

February 1983

JOHN WILEY \& SONS, InC. 605 Third Avenue

New York, N.Y. 10158

In Canada: 22 Worcester Road

Rexdale, Ontario M9W 1 L1 


\section{JOURNAL OF \\ PLASMA PHYSICS}


Journal of Plasma Physics exists for the publication of experimental and theoretical research papers on plasma physics and its applications.

\author{
EDITOR \\ DR J. P. DOUGHERTY \\ Department of Applied Mathematics and Theoretical Physics, University of Cambridge, \\ Silver Street, Cambridge CB3 $9 E W$, England \\ ASSOCIATE EDITORS \\ Prof. D. BERSHADER \\ Department of Aeronautics and Astronautics, \\ Stanford University, Stanford, California 94305, U.S.A. \\ PROT. F. D. KAHN \\ Department of Astronomy, \\ University of Manchester, Manchester M13 9PL, England \\ Prof. W. B. THOMPSON \\ Department of Physics, \\ University of California, La Jolla, California 92093, U.S.A.
}

Authors wishing to have papers published in the JoURNAL should communicate them to any one of the persons named above, choosing one in their own country where possible.

Authors are urged to ensure that their papers are written clearly and attractively, in order that their work will be readily accessible to readers.

Manuscripts should be typed in double spacing on one side of the paper only, with references listed at the end in alphabetical order of authors. Drawings should be done in Indian ink on plain white or transparent paper, and should not be larger than $15 \mathrm{in}$. by $24 \mathrm{in}$. Lettering should be shown clearly in pencil for reproduction by the printer, and as far as possible information relating to a figure should be placed in the caption rather than on the figure. A typed list of captions should be provided at the end of the manuscript. Proofs of papers from overseas will usually be despatched to authors by airmail. There is no charge for publication. Authors are entitled to receive 50 offprints of a paper in the J OU R NAL free of charge, and additional offprints can be purchased if ordered in advance.

$$
\text { (C) Cambridge University Press } 1982
$$

\title{
Copying
}

This journal is registered with the Copyright Clearance Center, 21 Congress St., Salem, Mass. 01970. Organizations in the U.S.A. who are also registered with C.C.C. may therefore copy material (beyond the limits permitted by sections 107 and 108 of U.S. copyright law) subject to payment to C.C.C of the per copy fee of $\$ 02.50$. This consent does not extend to multiple copying for promotional or commercial purposes. Code 0022-3778/82/2828-0001\$02.50.

ISI Tear Service, 3501 Market Street, Philadelphia, Pennsylvania 19104, U.S.A., is authorized to supply single copies of separate articles for private use only.

For all other use, permission should be sought from the Cambridge or New York offices of the Cambridge University Press.

JouRnal of Plasma Phy ICS (ISSN 0022-3778) is published once every two months in February, April, June, August, October and December, by Cambridge University Press, The Edinburgh Building, Shaftesbury Road, Cambridge CB2 2RU and 32 East 57th Street, New York, N.Y. 10022.

Three parts form a volume. The subscription price (which includes postage)

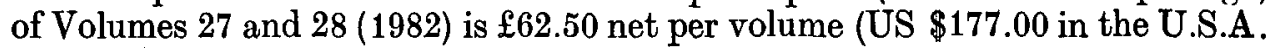
and Canada) for institutions; $£ 31.25$ (US $\$ 88.50$ ) per volume for individuals. Single parts cost $£ 23.50$ each (US $\$ 66.50$ in the U.S.A. and Canada) plus postage. All orders must be accompanied by payment.

Copies of the journal for subscribers in the United States of America and Canada are sent by air to New York to arrive with minimum delay.

Second class postage paid at New York, N.Y., and at additional mailing offices. POSTMASTER: send address changes in U.S.A. and Canada to Cambridge University Press, 32 East 57 th Street, New York, N.Y. 10022. 


\section{JOURNAL OF}

\section{PLASMA PHYSICS}

VOLUME 28

1982

CAMBRIDGE UNIVERSITY PRESS

CAMBRID GE

LONDON NEW YORK NEW ROCHELLE

MELBOURNE SYDNEY 
Published by the Press Syndicate of the University of Cambridge The Pitt Building, Trumpington Street, Cambridge CB2 1RP 32 East 57th Street, New York, N.Y. 10022

(c) Cambridge University Press 1982

Printed in Great Britain at the University Press, Cambridge 


\section{CONTENTS TO VOLUME 28}

\section{Part 1 A UGUST 1982}

Hydrodynamic theory of drift Kelvin-Helmholtz instabilities. A. B. MIKHAILOVSKII

Stationary waves at the interface between a plasma stream and a magnetic field. B. K. Shivamoggi

Filamentation and collapse of Langmuir waves in a weak magnetic field. P. Rolland and S. G. TAgare

Electron acceleration by stochastic wave packets. P. RoLLAND

On the evolution of normal ionizing shock waves in helium. V. S. SYNAKH and V. V. ZaKaJdakov

Thermal conductivity in a laser-created plasma heated by inverse bremsstrahlung absorption. R. BALESCU

Wave propagation in the presence of a spatially uniform external periodic magnetic field in two-temperature plasma. S. K. GHosH

Finite- $n$ ballooning mode theory for axisymmetric toroidal plasmas. R. W. Moore and D. DobrotT

Stability of a positive column in the presence of an axial magnetic field. M. S. UBERoI and C. Y. CHOW

Alfvén soliton in a low-beta plasma. P. K. Shukla, H. U. Rahman and R. P. SHaRma

Computer simulation of synchrotron radiation in two dimensions. $\mathrm{L}$. T. Wana, J. M. Dawson, A. T. Lin, C. R. Menyuk and T. Tajima

A formulation for computation of a class of collision-free plasmas in two dimensions. J. W. DUNGEY

Decay of the lower-hybrid wave into an ion cyclotron mode and a whistler wave. M. K. SAXENA

Nonlinear transient signal propagation in homogeneous plasma. D. Jovanović, H. L. PÉcseli and K. Thomsen

The effects of thermal motion of neutrals on the non-potential instabilities in a weakly ionized sodium plasma. V. J. ŻGMAN and B. S. MILIć

Constitutive relation for slowly varying warm plasmas. K. SUCHY

\section{PART 2 OCTOBER 1982}

Anomalous transport coefficients in a magnetized turbulent plasma. X. QIU and R. BALESCU

Nonlinear wave interactions in a collisionless space and time dependent warm fluid plasma. J. LaRsson

A study of the mass ratio dependence of the mixed species collision integral. A. J. M. GarRETT

The effect of magnetic shear on the crossfield current-driven ion-acoustic instability. R. Bharuthram and M. A. Hellberg

A linear and quasi-linear investigation of the crossfield current-driven ion-acoustic instability. R. Bharuthram and M. A. Hellberg 
Investigation of plasma-wall interaction by $\mathrm{H}$ alpha resonant scattering in the tokamak UNITOR. G. ReINhold, J. HaCkMANN and J. UHLENBUSCH

The mean electromotive force generated by random Alfvén waves in a collisionless plasma under a non-uniform mean magnetic field. $T$. Namikawa and H. Hamabata

The mean electromotive force generated by random hydromagnetic waves in a collisionless plasma. T. Namikawa, H. Hamabata and Y. Hosoya

The mean electromotive force generated by random Alfvén waves in a collisionless non-uniform plasma. H. Hamabata, T. Namikawa and Y. Hosoya

Similarity solutions for nonlinear damping of Alfvén waves. J.F. McKenzIE

Magneto-acoustic oscillations as a plasma diagnostic technique for a current-carrying plasma column. M. H. Brennan, A. L. MCCarthy and M. L. SAwLEY

Fast magnetic field-line reconnexion in a compressible fluid. Part 1. Coplanar field lines. A. M. Soward and E. R. Priest

Cylindrical plasma equilibria maintained by means of a rotating magnetic field. W. N. Hugrass

Part 3 December 1982

Stability of solitary wave solutions of simultaneous nonlinear Schrödinger equations. J. C. Bhakta and M. R. Gupta

The crossfield current-driven ion-acoustic instability in a collisional plasma. R. Bharuthram, M. A. Hellberg and R. D. Lee

The shear Alfvén continuous spectrum of axisymmetric toroidal equilibria in the large aspect ratio limit. C. E. Kieras and J. A. Tataronis

Fast magnetic field-line reconnexion in a compressible fluid. Part 2. Skewed field lines. A. M. Soward

Generalized expressions for momentum and energy losses of charged particle beams in non-Maxwellian multi-species plasmas and spherical symmetry. S. Cuperman, I. Weiss and M. Dryer

Evolution of nonlinear Alfvén waves propagating along the magnetic field in a collisionless plasma. M. KHANNA and R. RAJARAM

Growth rates of bending $\mathrm{KdV}$ solitons. E. W. LAEDKE and $\mathrm{K} . \mathrm{H}$. SPatscheK

Stochasticity in plasmas with electromagnetic waves. J. T. MendonçA and F. DoveIL

Nonlinear stability of doublets against axisymmetric resistive MHD modes. T. H. JENSEN and F. W. MoClain

Electromagnetic cyclotron-loss-cone instability associated with weakly relativistic electrons. H. K. Wong, C.S. WU, F. J. KE, R. S. SCHNEIDER and L. F. ZIEBELL

Lower-hybrid instability in current-carrying plasmas. J. E. WILLETT and H. MeHDian 
Nonlinear interaction of spherical waves in a homogeneous isotropic plasma. J. C. Cerisier

Collisionless electrostatic interchange instabilities. S. P. GARY and M. F. Thomsen

Energy transfer in magnetized plasmas. L. NOCERA 565

Author Index to Voldme 28 
Continued from back cover

Lower-hybrid instability in current-carrying plasmas

J. E. WILLETT AND H. MEHDIAN

527

Nonlinear interaction of spherical waves in a homogeneous isotropic plasma

J. C. CERISIER

539

Collisionless electrostatic interchange instabilities

S. P. GARY AND M. F. THOMSEN

Energy transfer in magnetized plasmas

L. NOCERA

565

AUTHOR INDEX TO VOLUME 28

575 


\section{JOURNAL OF PLASMA PHYSICS}

Volume 28 Part 3 December 1982

CONTENTS

Stability of solitary wave solutions of simultaneous nonlinear

Schrödinger equations

J. C. BHAKTA AND M. R. GUPTA

page 379

The crossfield current-driven ion-acoustic instability in a

collisional plasma

R. BHARUTHRAM, M. A. HELLBERG AND R. D. LEE

385

The shear Alfvén continuous spectrum of axisymmetric toroidal equilibria in the large aspect ratio limit

C. E. KIERAS AND J. A. TATARONIS

Fast magnetic field-line reconnexion in a compressible fluid.

Part 2. Skewed field lines

A. M. SOW A R D

Generalized expressions for momentum and energy losses of charged particle beams in non-Maxwellian multi-species plasmas and spherical symmetry

S. CUPERMAN, I. WEISS AND M. DRYER

Evolution of nonlinear Alfvén waves propagating along the magnetic field in a collisionless plasma

M. KHANNA AND R. RAJARAM

Growth rates of bending $\mathrm{KdV}$ solitons

E. W. LAEDKE AND K. H. SPATSCHEK

Stochasticity in plasmas with electromagnetic waves

J. T. MENDONÇA AND F. DOYEIL

Nonlinear stability of doublets against axisymmetric resistive MHD modes

T. H. JENSEN AND F. W. MCCLAIN

Electromagnetic cyclotron-loss-cone instability associated with weakly relativistic electrons

H. K. WONG, C. S. WU, F. J. KE, R. S. SCHNEIDER AND

L. F. Z I E B E L L

Continued on inside back cover

(C) Cambridge University Press 1982

\section{CAMBRIDGE UNIVERSITY PRESS}

THE PITT BUILDING, TRUMPINGTON STREET, CAMBRIDGE CB2 1 RP

32 EAST 57TH STREET, NEW YORK, N.Y. 10022

Printed in Great Britain at the University Press, Cambridge 